\title{
Analysis of Precipitation Variation and Trend Forecast in Huashan Area of China
}

\author{
Hou Kai, Li Yabin, Qian Hui \\ Environmental Science and Engineering, Chang'an University College, Shanxi Xi'an, China
}

\section{Email address:}

1123997326@qq.com (Hou Kai),893378831@qq.com (Li Yabin), 55480981@qq.com (Qian Hui)

\section{To cite this article:}

Hou Kai, Li Yabin, Qian Hui. Analysis of Precipitation Variation and Trend Forecast in Huashan Area of China. Science Discovery. Vol. 4, No. 3, 2016, pp. 183-188. doi: 10.11648/j.sd.20160403.15

Received: March 13, 2016; Accepted: April 15, 2016; Published: July 5, 2016

\begin{abstract}
In order to mitigate the adverse effects of drought, floods and other natural disasters on agriculture, and to provide a reliable climate foundation for agricultural structure adjustment, spatial and temporal variation of precipitation in Huashan Mountain needs further research and exploration. This paper based on rainfall data from 1964 to 2013 Shaanxi Huashan station (57046) weather station, using regression analysis and Mann-Kendall nonparametric test, systematically and comprehensively analyzed spatial and temporal variation of precipitation in Huashan Mountain for nearly 50 years. The results showed that: from 1964 to 2013, the mean annual precipitation in Huashan area of Shaanxi Province generally presented a declining trend, and declined significantly. The average monthly rainfall of Huashan area in summer and autumn was higher than the rainfall in spring and winter over the last 50 years. As to the rainy month changes, rainfall from March to April and September to October represented significantly declining in Huashan area of Shaanxi Province, but from January to February, May to August, and November to December rainfall decreased slowly. In spring and autumn, variation trend of rainfall was clear in downward trend; while in summer and winter, variation trend of rainfall is not obvious in downward trend as well.
\end{abstract}

Keywords: Regression Analysis, Mann-Kendall Test, Precipitation, Trend Test, Variation

\section{中国华山地区降水变化及趋势预测分析}

侯凯，李亚斌，钱会

环境科学与工程学院, 长安大学, 陕西西安, 中国

\section{邮箱}

1123997326@qq. com（侯凯），893378831@qq.com（李亚斌），55480981@qq.com（钱会）

\begin{abstract}
摘要: 为了减轻干旱、洪涝等自然灾害对农业产生的不利影响, 以及为农业产业结构调整提供气候依据, 需要对中国华 山降水的时空变化特征做进一步的研究与探索。本论文以中国陕西省华山站（57046）气象站1964～2013年的降雨资料为 基础, 运用回归分析法与Mann-Kenda11非参数检验法的对比分析, 系统全面的分析了近50年来华山降水的时空变化特征。 分析结果表明：1964 2013年陕西华山地区的年平均降雨量总体呈下降趋势，而且下降趋势很明显；50年间华山地区月 平均降雨量中夏季与秋季的降雨量大于春季与冬季的降雨量; 在月变化上, 陕西华山地区 $3 \sim 4$ 月份与 $9 \sim 10$ 月份的降雨量 都呈明显的下降趋势，但1 2月份、5 8月份以及11 12月份的降雨量都呈比较小的下降趋势; 春季与秋季降雨量特征 变化趋势很明显, 而且都为下降趋势; 但夏季与冬季的降雨量特征变化趋势不明显, 也都呈下降趋势。
\end{abstract}

关键词：回归分析法, Mann-Kenda11, 降水, 趋势检验, 变化特征 


\section{1. 引言}

目前, 全球气候变化已经成为各国政府、科学界和公 众普遍关注的一个热点问题, 特别是关于全球气候变暖与 全球降水量的变化最为引人注意。根据大量的研究表明, 降水量在高纬度大部分地区呈增加的态势, 中低纬度大部 分地区则是减少 ${ }^{[1]}$ 。杨宏青等认为长江流域年、夏季 6-8 月的暴雨日数和暴雨量表现为较大范围的增加趋势 ${ }^{\left[{ }^{[2]}\right.}$ 。翟 盘茂等研究发现中国降水总量变化趋势不明显, 但在空间 特征变化上比较明显, 而且极端降水强度在增强 ${ }^{[3-4]}$ 。

降雨量过大可能引起地区干旱、山洪、山体滑坡、泥 石流等自然灾害, 所以降雨量的大小起着重要影响, 而且 降雨量也是农作物种植区划分区的基础资料。研究陕西华 山地区的降水时空变化规律, 对预防上述提到的自然灾害 的气候变化规律和合理规范农作物种植区域具有重要的 意义; 特别是在全球气候恶化, 以及温室效应的背景下, 极端天气、气候事件频率加剧, 可能导致许多突发性的气 象灾害, 对公共财产以及人们的生命安全都有极大的威胁。 所以, 应该加强与完善气象灾害预警的工作, 防患于未然。

中国华山地区虽然是一个比较小的区域, 但它作为陕 西地区的优质水果与蔬菜的产地, 以及作为一个著名的旅 游地区, 华山地区的气象灾难预警显得格外重要。所以, 本论文在对陕西华山降水的时空变化特征进行深入的了 解后, 便可采取适当的技术手段应对因降水变化而对农业 以及种植业产生的不利影响; 而且对于华山地区旅游业的 发展, 特别是对于危险天气的预测都有帮助, 降低了游客 爬山时遇到危险的程度, 保障了人们的人身安全, 同时也 对华山地区旅游业的发展起了一个推动作用。本文以陕西 省华山站 (57046) 气象站降水资料为基础, 运用回归分 析法与Mann-kenda11非参数检验法的对比分析, 对陕西华 山全区的降水变化特征进行分析与研究。

\section{2. 研究区简介}

华山位于陕西渭南华阴市境内, 处于北纬 $34^{\circ} 25^{\prime} \sim 34^{\circ} 00^{\prime}$, 东经 $109^{\circ} 57^{\prime} \sim 110^{\circ} 05^{\prime}$ 之间。 东西长15千米, 南北宽 10 千米, 景域面积约148平方千米。 西距陕西省会西安 120 千米。华山远离海洋, 又处于西风 带北纬 $30^{\circ}-60^{\circ}$ 之间, 大陆度为 $53^{\circ} 7^{\prime}$, 属于暖温带 大陆性季风气候。北麓 (华阴站) 降水量为 600 毫米, 南 麓 (洛南) 为 725 毫米, 顶峰 (华山站) 为 925 毫米。 1000-1400米间, 为多雨带或最大降水带。

\section{3. 研究资料与研究方法}

\section{1 . 资料}

文中所用资料为陕西省华山站 (57046)气象站1964 2013年逐日降水量。本文对所有的资料进行了分析处理, 去掉了其中的错误记录, 缺测或空白记录引用《近 50 年来 渭河流域降水变化特征分析》中的部分数据。

\section{2. 研究方法}

趋势分析方法通常有线性拟合、滑动平均、累积距平、 二次平滑、三次样条函数、Kenda11秩次相关法、 Mann-Kenda11秩次相关法等。在时间序列趋势分析中, Mann-Kendal1 非参数秩次相关检验法是世界气象组织推 荐并已广泛使用的非参数检验方法 ${ }^{[5]}$, 因此本论文采用该 方法来分析陕西华山降水随时间序列变化趋势和变化的 显著程度。

\subsection{1. 回归分析法}

回归分析法是水文统计学中常用到的一种分析方法, 主要包括线性回归和非线性回归, 线性回归又可分为一元 线性回归和多元线性回归, 本文主要采用一元线性回归法。

\section{2.2. Mann-Kendal 1 非参数检验法}

Mann-Kendall是一种非参数检验方法, 最初由Mann 和 Kenda11 两位学者提出原理并研究发展的。 Mann-Kenda11检验不需要样本遵从一定的分布, 也不受少 数异常值的干扰, 适用于非正态分布的数据, 如水文、气 象等数据。在Mann-Kenda11检验中, 对于具 有 $\mathrm{n}$ 个样本的 时间序列数据 $X_{i}=\left(x_{1}, x_{2}, \ldots, x_{n}\right)$, 先确定所有的对偶值 $\left(x_{i}, x_{j}, j>i\right)$ 中 $x_{i}$ 与 $x_{j}$ 的大小关系。趋势检验的统计变量 S计算如下式:

$$
S=\sum_{i=1}^{n} \sum_{j=1}^{i-1} \operatorname{sgn}\left(x_{i}-x_{j}\right)
$$

在这个式子当中, $\mathrm{S}$ 为正态分布, 其均值为 0 。其中, $X_{i} 、 X_{j}$ 为要进行检验的随机变量, $n$ 为序列长度; 当 $x$ 大于、 等于或小于 0 时, $\operatorname{sgn}(x)$ 的值分别是 $1 、 0 、-1$ 。

然后其方差的表达式为:

$$
\operatorname{Var}(s)=n(n-1)(2 n+5) / 18
$$

当 $n>10$ 时, 标准的正态统计变量可以通过以下式子 进行计算:

$$
Z=\left\{\begin{array}{cc}
(s-1) / \sqrt{\operatorname{var}(s)} s & s>0 \\
0 & s=0 \\
(s+1) / \sqrt{\operatorname{var}(s)} & s<0
\end{array}\right.
$$

该序列在原假设中是无趋势的, 接着采用双边趋势法 去检验结果, 在给定的显著性水平 $\gamma$ 下, 如果其中的 $|Z| \geq Z_{1-\gamma / 2}$, 则我们可以拒绝原来的假设, 也就是在 $\gamma$ 置 信水平上, 时间的序列数据在一定程度上存在着比较明显 的上升或者下降的趋势, 但是若 $|Z|<Z_{1-\gamma / 2}$ 时, 则证明 原假设正确, 即接受原假设, 可以考虑为变化趋势不是很 明显。对于统计变量 $Z$, 当 $Z>0$ 时, 表示趋势是呈上升的趋 势; 当 $Z<0$ 时, 表示趋势是呈下降的趋势。当其绝对值大 
于等于 $1.28 、 1.64$ 和 2.33 时分别表示通过了置信度为 $90 \%$ 、 $95 \%$ 和 $99 \%$ 的显著性检验。

使用Mann-Kenda11还可用于突变性检验分析, 进行检 验序列突变时, 其统计量与趋势分析的统计量 $Z$ 有所不同。 进行突变性检验, 需要对样本序列 $X i$, 构造一秩序列:

$$
\begin{aligned}
& S_{k}=\sum_{i=1}^{k} \sum_{j}^{i-1} \alpha_{i j} \\
& \alpha_{\mathrm{ij}}=\left\{\begin{array}{ll}
1 & x_{i}>x_{j} \\
0 & x_{i} \leq x_{j}
\end{array} \quad 1 \leq j \leq i\right. \\
& U F_{k}=\frac{\left|S_{k}-E\left(S_{k}\right)\right|}{\sqrt{\operatorname{Var}\left(S_{k}\right)}}
\end{aligned}
$$

其中:

$$
\begin{aligned}
& E\left(S_{k}\right)=k(k+1) / 4 \\
& \operatorname{Var}\left(S_{k}\right)=k(k-1)(2 k+5) / 72
\end{aligned}
$$

将时间序列按逆序排列，再按照上式计算，同时 $U B_{k}$ 的计算公式:

$$
\left\{\begin{array}{l}
U B_{k}=-U F_{k} \\
k=n+1-k
\end{array}\right.
$$

以上所有式中 $k=1,2,3 \cdots n ; n=53$ 。若 $U F_{k}$ 值大于 0 , 表 明序列呈上升趋势, 小于 0 呈下降趋势; 当 $U F_{k}$ 超过置信度 线 (1.9) 时, 表明上升或下降趋势明显; 如果在置信度 线之间, $U F_{k}$ 与 $U B_{k}$ 两条曲线有交叉点, 那么交叉点对应的 时刻是序列突变开始的时刻。

\section{4. 陕西华山的降水变化特征分析}

\section{1. 华山年平均降雨量变化趋势分析}

由图1可以看出, 在年际变化上, 除了一些个别的年 份外，陕西华山从1964 2013年的年平均降雨量的年际波 动幅度不是很大, 但是总体上是呈现逐年减少的趋势, 由 最开始的 $920 \mathrm{~mm}$ 左右逐渐减少到了现在的 $600 \mathrm{~mm}$ 左右。其中 降雨量的最小值为 $465 \mathrm{~mm}$, 出现在了 1997 年, 排名第二小 的是 2001 年的 $509 \mathrm{~mm}$, 最大降雨量的是 1964 年, 它的雨量 达到了 $1262 \mathrm{~mm}$ 。利用Mann-Kendal1检验法对陕西华山的年 降雨量的变化趋势进行检验, 通过计算可以得到其统计量 值Z为 -3.06 , 这说明陕西华山年降雨量是随时间呈下降的 趋势，而且因为其绝对值大于 2.33 , 所以证明通过了 $99 \%$ 的置信度检验, 证明这种变化趋势很显著。

\section{2. 华山降雨年内月平均降雨量变化趋势分析}

由表1与图2可以看出，统计1964 2013年50年间的 12 个月份月平均降雨量以及其所占到的百分比, 按照传统的 季节划分标准, 把陕西华山划分为春季 (3-5月), 夏季 (6-8月), 秋季 (9-11月), 冬季 (当年 12 月一翌年 2 月), 然后对各季降雨量进行分析可以看出夏季与秋季的降雨

\begin{tabular}{|c|c|c|c|c|c|c|c|c|c|c|c|c|}
\hline 时间 & 1月 & 2月 & 3月 & 4月 & 5月 & 6月 & 7月 & 8月 & 9月 & 10月 & 11月 & 12月 \\
\hline 降水量/mm & 13. 04 & 17.88 & 40. 16 & 62.14 & 84.55 & 85.91 & 160.1 & 126.5 & 115.6 & 79. 69 & 33.15 & 11.31 \\
\hline 百分比/\% & 1.57 & 2. 15 & 4. 84 & 7. 49 & 10.19 & 10.35 & 19. 29 & 15.25 & 13.93 & 9.61 & 3.99 & 1. 34 \\
\hline
\end{tabular}
量比春季与冬季的降雨量要多, 夏季最高可以达到 $160 \mathrm{~mm}$, 秋季最高可以达到 $115 \mathrm{~mm}$, 而春季与冬季最低时为 $11 \mathrm{~mm}$ 。



图1 1964-2013年华山年降雨量特征变化趋势。

表1 华山地区年内降雨量百分比分配。

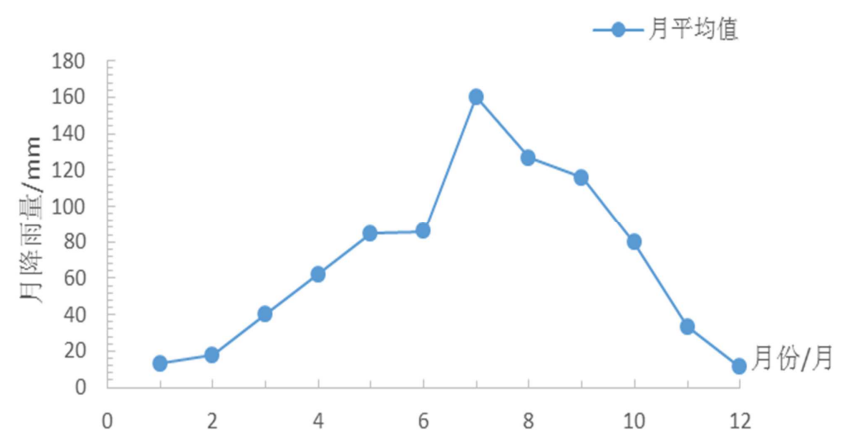

图2 1964-2013年华山月平均降雨量特征变化趋势。

\section{3. 陕西华山年际降水突变分析}

根据Mann-Kenda11检验法可得到, 陕西华山地区的年 降水量通过了 $90 \%$ 的置信度显著性实验。根据图3信息可得 知, 华山地区的突变点较多, 说明年降水变化情况比较的 复杂; 1964-1969年的降水偏多, 而且可以看出, 在1968 年的时候是一个显著增加的年份; 从图中还可以看出从 1971年以后降雨量基本上呈现下降的趋势, 没有上升的趋 势, 但是下降趋势不是很明显, 说明自1971年以后陕西华 山地区的降雨在不断的减少。 


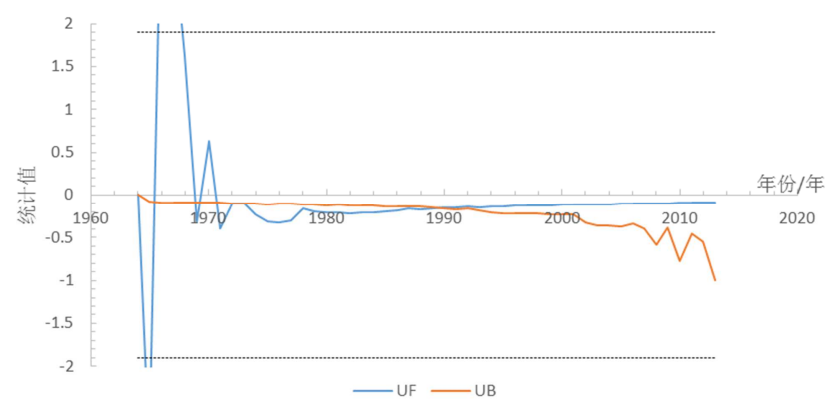

图3 华山地区年降水量的Mann-Kenda11检验。

\section{4. 陕西华山四个季度降雨量的线性回归变化趋势}



图4 1964-2013年华山春季降雨量特征变化趋势。

从图3可以看出，1964 2013年50年间的春季降雨量 的变化趋势, 由一元线性回归方程 $y=-2.1175 x+$ 4397.1可以得到, 它的平均下降率为 2.1175 , 特征变化 趋势呈下降趋势而且很明显, 其中降雨量的最小值为 $80.1 \mathrm{~mm}$, 出现在1997年, 最大降雨量在1964年, 降雨量 为 $315.6 \mathrm{~mm}$ 。

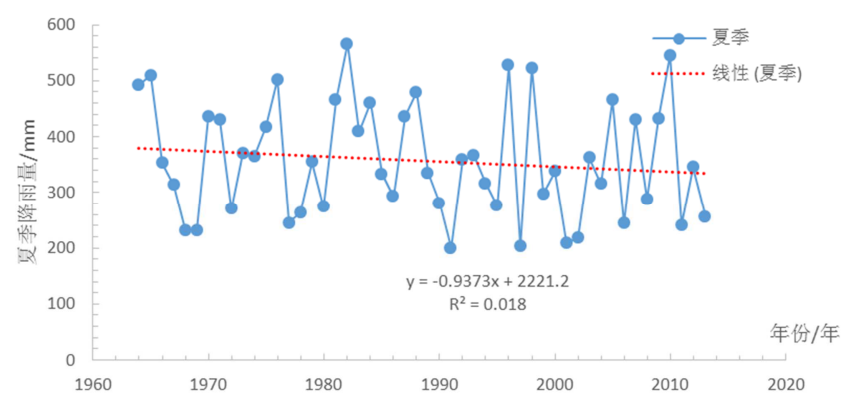

图5 1964-2013年华山夏季降雨量特征变化趋势。

从图4可以看出, 1964 2013年50年间的夏季降雨量的 变化趋势, 由一元线性回归方程 $y=-0.9373 x+2221.2$ 可以得到, 它的平均下降率为 0.9373 , 特征变化趋势呈下
降趋势但不明显, 其中降雨量的最小值为 $199.8 \mathrm{~mm}$, 出现 在1991年, 最大降雨量在1982年, 降雨量为 $565.8 \mathrm{~mm}$ 。

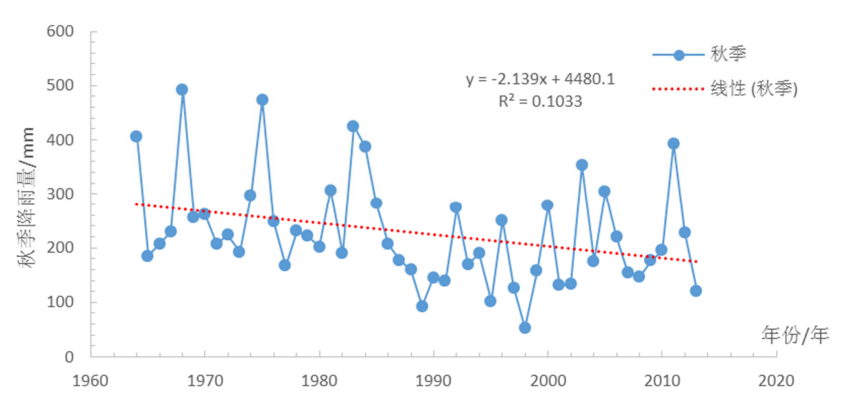

图6 1964-2013年华山秋季降雨量特征变化趋势。

从图5可以看出, 1964 2013年50年间的秋季降雨量 的变化趋势, 由一元线性回归方程 $y=-2.139 x+$ 4480.1可以得到, 它的平均下降率为 2.139 , 特征变化趋 势呈下降趋势而且很明显, 其中降雨量的最小值为 $53.1 \mathrm{~mm}$, 出现在1998年, 最大降雨量在1968年, 降雨量 为 $491.8 \mathrm{~mm}$ 。

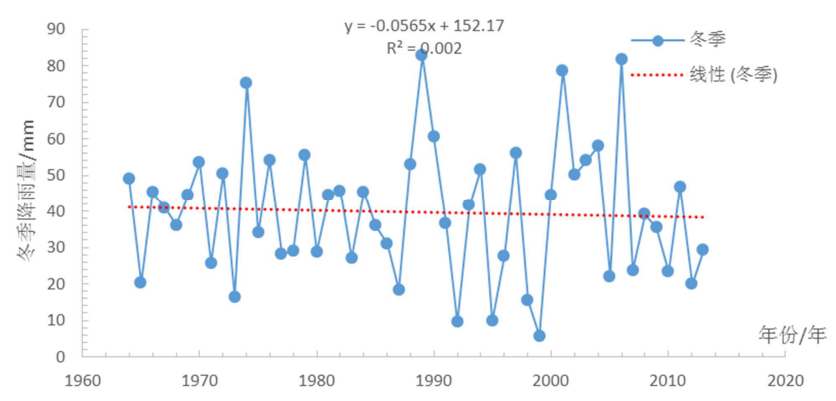

图7 1964-2013年华山冬季降雨量特征变化趋势。

从图6可以看出, 1964 2013年50年间的冬季降雨量的 变化趋势, 由一元线性回归方程 $y=-0.0565 x+152.17$ 可以得到, 它的平均下降率为 0.0565 , 特征变化趋势呈下 降趋势但不明显, 其中降雨量的最小值为 $5.8 \mathrm{~mm}$, 出现在 1999年, 最大降雨量在 1989 年, 降雨量为 $82.7 \mathrm{~mm}$ 。

\section{5. 华山地区12个月份的Mann-Kend11非参数检验}

对陕西华山地区的 12 个月份运用Mann-kend11非参数 检验法, 得到 12 个月份的 $S$ 值与 Z值见表 1 。

表2 华山地区 12 个月份 $S$ 值与 $Z$ 值计算结果。

\begin{tabular}{lllllllllllll}
\hline 月份 & $\mathbf{1}$ & $\mathbf{2}$ & $\mathbf{3}$ & $\mathbf{4}$ & $\mathbf{5}$ & $\mathbf{6}$ & $\mathbf{7}$ & $\mathbf{8}$ & $\mathbf{9}$ & $\mathbf{1 0}$ & $\mathbf{1 1}$ & $\mathbf{1 2}$ \\
\hline $\mathrm{S}$ 值 & -46 & -23 & -286 & -442 & -56 & -72 & -35 & -82 & -179 & -277 & -110 & -18 \\
$\mathrm{Z}$ 值 & 0.38 & 0.18 & 2.38 & 3.69 & 0.46 & 0.59 & 0.28 & 0.68 & 1.49 & 2.31 & 0.91 & 0.14 \\
\hline
\end{tabular}

根据表 1 可以看出: 1 月份的趋势检验的统计变量 $S=-46, Z=-0.38<0$, 证明1964 2013年1月份降雨量的特 征变化趋势呈下降趋势, 且 $|Z|=0.38<1.28$, 表明没有通 过置信度为 $90 \%$ 的显著性检验, 证明变化趋势不是很明显;
2 月份的趋势检验的统计变量 $\mathrm{S}=-23, \mathrm{Z}=-0.18<0$, 证明 1964 2013年2月份降雨量的特征变化趋势呈下降趋势, 且 $|Z|=0.18<1.28$, 表明没有通过置信度为 $90 \%$ 的显著性检验, 证明变化趋势不明显; 3 月份的趋势检验的统计变量 
$S=-286, Z=-2.38<0$, 证明1964 2013年3月份降雨量的特 征变化趋势呈下降趋势, 且 $|Z|=2.38>2.33$, 表明通过置 信度为 $99 \%$ 的显著性检验, 证明变化趋势很明显; 4月份的 趋势检验的统计变量 $S=-442, Z=-3.69<0$, 证明 $1964 \sim 2013$ 年 4 月份降雨量的特征变化趋势呈下降趋势, 且 $|Z|=3.69>2.33$, 表明通过置信度为 $99 \%$ 的显著性检验, 证 明变化趋势很明显; 5 月份的趋势检验的统计变量 $S=-56$, $Z=-0.46<0$, 证明1964 2013年5月份降雨量的特征变化趋 势呈下降趋势, 且 $|Z|=0.46<1.28$, 表明没有通过置信度 为 $90 \%$ 的显著性检验, 证明变化趋势不明显; 6月份的趋势 检验的统计变量 $S=-72, Z=-0.59<0$, 证明 1964 2013年6 月份降雨量的特征变化趋势呈下降趋势, 且 $|Z|=0.59<1.28$, 表明没有通过置信度为 $90 \%$ 的显著性检验, 证明变化趋势不明显; 7月份的趋势检验的统计变量 $\mathrm{S}=-35$, $Z=-0.28<0$, 证明1964 2013年7月份降雨量的特征变化趋 势呈下降趋势, 且 $|Z|=0.28<1.28$, 表明没有通过置信度 为90\%的显著性检验, 证明变化趋势不明显; 8月份的趋势 检验的统计变量 $S=-82, Z=-0.68<0$, 证明 $1964 \sim 2013$ 年 8 月份降雨量的特征变化趋势呈下降趋势, 且 $|Z|=0.68<1.28$, 表明没有通过置信度为 $90 \%$ 的显著性检验, 证明变化趋势不明显; 9 月份的趋势检验的统计变量 $S=-179, Z=-1.49<0$, 证明1964 2013年9月份降雨量的特 征变化趋势呈下降趋势, 且 $|Z|=1.49>1.28$, 表明通过置 信度为 $90 \%$ 的显著性检验, 证明变化趋势比较明显; 10 月 份的趋势检验的统计变量 $S=-277, Z=-2.31<0$, 证明 1964 2013年10月份降雨量的特征变化趋势呈下降趋势, 且 $2.33>|Z|=2.31>1.64$, 表明通过置信度为95\%的显著性 检验, 证明变化趋势很明显; 11月份的趋势检验的统计变 量 $S=-110, Z=-0.91<0$, 证明 1964 2013年11月份降雨量 的特征变化趋势呈下降趋势, 且 $|Z|=0.91<1.28$, 表明没 有通过置信度为 $90 \%$ 的显著性检验, 证明变化趋势不是很 明显; 12 月份的趋势检验的统计变量 $S=-18, Z=-0.14<0$, 证明1964 2013年12月份降雨量的特征变化趋势呈下降趋 势, 且 $|Z|=0.14<1.28$, 表明没有通过置信度为 $90 \%$ 的显著 性检验, 证明变化趋势不明显。

根据以上证明: 在月变化上, 陕西华山地区3 4月份 与9 10月份的降雨量特征变化趋势很明显, 而且都呈下降 趋势; 1 2月份、5 8月份以及11 12月份的降雨量特征 变化趋势不明显, 但都呈特别小的下降趋势。

\section{6. 华山地区四个季度的Mann-Kend11非参数检验}

对陕西华山地区的四个季度进行Mann-Kend11非参数 检验, 可以得到四个季度的 $S$ 值与 $Z$ 值, 结果见表 2 。

表3 华山地区四个季度的S值与 $Z$ 值计算结果。

\begin{tabular}{ccccc}
\hline 季度 & 春季 & 夏季 & 秋季 & 冬季 \\
\hline $\mathrm{S}$ 值 & -443 & -107 & -307 & -48 \\
$\mathrm{Z}$ 值 & -3.69 & -0.887 & -2.55 & -0.393 \\
\hline
\end{tabular}

根据表 3 可以看出: 春季的趋势检验的统计变量 $S=-443, Z=-3.69<0$, 证明1964-2013年春季的降雨量的
特征变化趋势呈下降趋势, 且 $|Z|=3.69>2.33$, 表明通过 了置信度为 $99 \%$ 的显著性实验, 证明变化趋势很明显; 夏 季的趋势检验的统计变量 $S=-107, Z=-0.887<0$, 证明 1964-2013年春季的降雨量的特征变化趋势呈下降趋势, 且 $|Z|=0.887<1.28$, 表明没有通过了置信度为 $90 \%$ 的显著 性实验, 证明变化趋势不明显; 秋季的趋势检验的统计变 量 $S=-307, Z=-2.55<0$, 证明 1964-2013年春季的降雨量 的特征变化趋势呈下降趋势, 且 $|Z|=2.55>2.33$, 表明通 过了置信度为 $99 \%$ 的显著性实验, 证明变化趋势很明显; 冬季的趋势检验的统计变量 $S=-48, \quad Z=-0.393<0$, 证明 1964-2013年春季的降雨量的特征变化趋势呈下降趋势, 且 $|Z|=0.393<1.28$, 表明没有通过了置信度为 $90 \%$ 的显著 性实验, 证明变化趋势不明显。

根据以上可以得到: 在季节的变化上, 陕西华山地区 的春季与秋季降雨量特征变化趋势很明显, 而且都为下降 趋势; 但夏季与冬季的降雨量特征变化趋势不明显, 也都 呈下降趋势。

\section{5. 结论与讨论}

本文利用了1964 2013年50年的降水资料、线性回归 法和Mann-Kendal1法, 系统的分析了陕西华山地区降雨量 的变化特征。

1）根据Mann-Kendal1趋势性检验，在1964 2013年 五十年间，陕西华山的年降雨量总体呈下降的趋 势变化, 由于统计量值 $|Z|=3.06>2.33$, 所以证明 通过了 $99 \%$ 的置信度检验, 证明这种变化趋势很显 著。

2）分析1964 2013年五十年间，陕西华山地区月降 雨量主要集中在夏季与秋季, 而在春季与冬季降 雨量较少。

3）运用一元线性回归与Mann-Kenda11趋势性检验法, 可以得到: 在1964 2013年五十年间, 华山地区 3 4月份与 9 10月份的降雨量特征变化趋势很明 显, 而且都呈下降趋势; 1月份、2月份、5月份、 6 月份、7月份、8月份、11月份、12月份的降雨量 特征变化趋势不明显, 但都呈特别小的下降趋势。

4）运用一元线性回归与Mann-Kendal1趋势性检验法, 可以得到: 春季与秋季降雨量特征变化趋势很明 显, 而且都为下降趋势; 但夏季与冬季的降雨量 特征变化趋势不明显, 也都呈下降趋势。

所以根据以上结论, 可以推知: 未来年间华山地区的 年降雨量可能会不断下降, 所以应该对农业作物的种植区 域进行优化，应对降雨量减少带来的问题，努力克服对农 作物的不利影响; 在夏季与秋季, 由于降雨量较全年来说 最多, 所以应该在夏季与秋季做好应对山洪、山体滑坡、 泥石流等自然灾害的措施, 把灾害的监测预报预警放到十 分突出的位置。

\section{致谢}

水利部公益性行业科研专项经费项目 (201301084)。 


\section{参考文献}

［1］施能, 黄先香, 杨扬 1948-2000 年全球陆地年降水量场趋 势变化的时、空特征 $[J]$. 大气科学, 2003, 27 (6) :971-982.

[2] 杨宏青, 陈正洪, 石燕, 等. 长江流域近 40 年强降水的变 化趋势 $[J]$. 气象，2005，31(3):66-68

[3] Zhai P. M., Sun A. J., Ren F. M., et al. Changes of Climate Extremes in China[J]. Climate Change, 1999, $42(1)$ : 203-218.

［4］翟盘茂, 邹旭恺. 1951-2003 年中国气温和降水变化及其对 干旱的影响 $[J]$. 气候变化研究进展, 2005, 1(1) : 16-18.

［5］曹洁萍, 迟道才, 武立强, 等. Mann-Kenda11 检验方法在 降水趋势分析中的应用研究 $[J]$. 农业科技与装备, 2008, $179(5): 35-40$.

［6］屈振江, 鲁渊平, 雷向杰. 陕西近 45a 各季气温和降水异常 时空特征分析 [J]. 干旱区资源与环境. 2010(07)

[7] 李爽, 王羊, 李双成. 中国近 30 年气候要素时空变化特征 [J]. 地理研究. 2009 (06)

[8] 刘扬, 韦志刚. 近 50 年中国北方不同地区降水周期趋势的 比较分析 $[J]$. 地球科学进展. 2012 (03)

[9] Honghton J T, Ding Y, Griggs D J, et al. Climate Change 2001: The Scientific Basis[M]. Cambridge: Cambridge University Press, 2001:881.

[10] Zuo H C, Lyu S H, Hu Y Q. Variations trend of yearly mean air temperature and precipitation in China in the last 50 years [J]. Plateau Meteorology, 2004, 23(2) : 238-244.

[11] Chen L X, Zhou X J, Li W L, et al. Characteristics of the climate change and its formation mechanism in China in last 80 years $[\mathrm{J}]$. Acta Meteorologica Sinica, 2004, 62 (5) :634-646.

[12] 贺伟, 布仁仓, 熊在平, 等. 1961-2005 年东北地区气温和 降水变化趋势 $[J]$.生态学报, 2013，33（2)：519-531.

[13] 王海军, 张勃, 赵传燕, 等. 中国北方近 57 年气温时空变 化特征 $[J]$. 地理科学进展, 2009, 2 (4): 643-650.

[14] 施雅风, 沈永平, 李栋梁, 等. 中国西北气候由暖干向暖湿 转型的特征和趋势探讨 $[J]$. 第四纪研究, 2003, 23 (2) : 152-164.

[15] 姜创业, 魏娜, 程肖侠, 等. 1961-2008 年陕西省年际气温 和降水区域性变化特征分析 $[\mathrm{J}]$. 水土保持研究, 2011, 18 (1): 197-200.

[16] 胡蓓蓓, 王军, 许世远, 等. 天津市近 50a 来降水变化分析 [J]. 干旱区资源与环境, 2009, $23(8)$ ：71-74.

[17] 李帅, 汤振权, 匡亚红. 湖北省 50 年来的气温和降水变化 趋势分析 $[J]$. 安徽农业科学, 2009, 37(4)：1652-1655.

[18］于延胜, 陈兴伟. R/S 和 Mann-Kendal1 法综合分析水文时 间序列未来的趋势特征 $[J]$. 干旱区资源与环境, 2008 , $19(3)$ : 41-44. 